\title{
Gestational trophoblastic disease: a profile of 37 cases
}

\author{
Sushruta Shrivastava $^{1}$, Manisha R. Gandhewar ${ }^{2}$
}

\author{
${ }^{1}$ Department of Obstetrics \& Gynecology, AIIMS, Bhopal, Madhya Pradesh, India \\ ${ }^{2}$ Department of Obstetrics \& Gynecology, ESI-PGIMSR, Andheri, Mumbai, Maharashtra, India
}

Received: 15 February 2014

Accepted: 8 March 2014

\author{
*Correspondence: \\ Dr. Sushruta Shrivastava, \\ E-mail: vikrantsush18@gmail.com
}

(C) 2014 Shrivastava $\mathrm{S}$ et al. This is an open-access article distributed under the terms of the Creative Commons Attribution Non-Commercial License, which permits unrestricted non-commercial use, distribution, and reproduction in any medium, provided the original work is properly cited.

\begin{abstract}
Background: Objective of current study was to study the demographic details, pattern of presentation and response to the treatment in the patients presenting with Gestational Trophoblastic Disease (GTD).

Methods: The present study was conducted in a tertiary teaching institute as a retrospective plus prospective study over a period of 5 years from August 2004 to August 2009. Total 37 cases were studied out of which 16 were studied retrospectively from the case record and 21 were studied prospectively. Patients were evaluated on the basis of their age, number of deliveries, history of abortion or molar pregnancy and the treatment received.

Results: 37 cases of gestational trophoblastic disease were studied in a period of 5 years from August 2004 to August 2009. The incidence of gestational trophoblastic disease was lin 600 deliveries with the mean age of patients being 26.9 years. Most common chief complaint at presentation was bleeding per vaginum after a period of amenorrhoea seen in 31 patients $(84 \%)$ followed by hyperemesis seen in $8(19 \%)$ patients. Out of 37 patients $29(78 \%)$ had complete mole \& $8(22 \%)$ had partial mole, the ratio of being 3.6:1. Complete cure rate in present study was seen in 31 out of $37(84 \%)$ patients and mortality was seen in $2.7 \%$.

Conclusions: Gestational trophoblastic disease is seen most commonly in reproductive age group. This is a highly curable tumor even in the presence of distant metastasis.
\end{abstract}

Keywords: GTD, Choriocarcinoma, Invasive mole, Chemotherapy

\section{INTRODUCTION}

Gestational Trophoblastic Disease (GTD) is a group of several diseases that includes the abnormal growth of cells inside the uterus. Unlike the cervical cancer or endometrial cancer, the cells of GTD do not develop from the cells of uterus; instead these tumors develop from the trophoblast layer that surrounds the embryo. These tumors start developing immediately following conception when the sperm from the male partner fertilizes the egg from the female. ${ }^{1}$

The spectrum of GTD ranges from benign condition like hydatidiform molar pregnancies (partial and complete) to malignant condition like invasive mole, persistent trophoblastic disease, choriocarcinoma, and placental site trophoblastic tumor. Occasionally, malignant growth may not become clinically evident until years after the last gestation. $^{2}$

All forms of GTD are characterized by a distinct tumor marker, the beta hCG. Cure rates of $100 \%$ in low-risk cases and $80 \%$ to $90 \%$ in high-risk cases are seen. ${ }^{3}$

The early stages of a pregnancy in which a GTD develops typically seem normal, then symptoms of the pregnancy are exaggerated for example the uterus may grow more rapidly than usual. The first obvious symptom is vaginal bleeding and lower abdominal cramps. It may also present with passage of grape like vesicles, hyperemesis, and signs and symptoms of preeclampsia. 


\section{METHODS}

The present study was conducted in a tertiary teaching institute as a retrospective plus prospective study over a period of 5 years from August 2004 to August 2009.

Total 37 cases were studied out of which 16 were studied retrospectively from the case records and 21 were studied prospectively.

Patients were evaluated on the basis of their age, number of deliveries, history of abortion or molar pregnancy and the treatment received. Detailed physical examination of local site was done. Investigations such as hemogram, renal and liver function tests, and serum beta hCG, X-ray chest and ultrasonography were done. WHO scoring was done for all patients.

Patients requiring chemotherapy were first given single agent chemotherapy with methotrexate (MTX) with following dose:

\section{MTX $1 \mathrm{mg} / \mathrm{kg} \mathrm{IM/IV} \mathrm{on} \mathrm{days} \mathrm{1,3,5,7}$}

FA $0.1 \mathrm{mg} / \mathrm{kg}$ PO on days $2,4,6,8$

The patients not responding to single agent chemotherapy were given multiple agent chemotherapy with EMACO regimen. The doses are as follow:

\section{Day 1}

Actinomycin D $0.5 \mathrm{mg}$ i.v. bolus

Etoposide $100 \mathrm{mg} / \mathrm{m}^{2}$ i.v. in $500 \mathrm{ml} \mathrm{N}$ saline over $30 \mathrm{~min}$

Methotrexate $100 \mathrm{mg} / \mathrm{m}^{2}$ i.v. push slowly

Methotrexate $200 \mathrm{mg} / \mathrm{m}^{2}$ i.v. in $500 \mathrm{ml} \mathrm{5 \%}$ dextrose over $12 \mathrm{hr}$.

\section{Day 2}

Actinomycin D $0.5 \mathrm{mg}$ i.v. bolus

Etoposide $100 \mathrm{mg} / \mathrm{m}^{2}$ i.v. in $500 \mathrm{ml} \mathrm{N}$ saline over $30 \mathrm{~min}$

Folinic acid 15 mg i.m. 12-hourly x 4 doses starting 30 hr. after commencing methotrexate

\section{Day 8}

Vincristine $1 \mathrm{mg} / \mathrm{m}^{2}$ i.v. bolus (max. $2 \mathrm{mg}$ )

Cyclophosphamide $600 \mathrm{mg} / \mathrm{m}^{2}$ i.v. in $500 \mathrm{ml} \mathrm{N}$ saline over $30 \mathrm{~min}$

During follow up patients were evaluated by physical examination, serum beta hCG levels \& ultrasound (whenever needed). Patients were asked about their menstrual cycle status during treatment \& follow up. Follow-up information was obtained up to August 2010. During follow up effective contraception was advised for all patients.

\section{RESULTS}

In the present study 37 cases of gestational trophoblastic disease were studied in a period of 5 years from August 2004 to August 2009. 16 were studied retrospectively from the case record and 21 were studied prospectively. Out of 21 prospective cases 4 cases lost to follow up \& out of 16 retrospective cases 1 patient lost to follow up.

Total deliveries occurred during this period were 22,082 . The incidence of gestational trophoblastic disease was $1.68 / 1000$ deliveries ( 1 in 600 deliveries). The age of the patients ranged from 17 to 45 years with a mean age of 26.9 years. Out of 37 patients 7 (19\%) were primigravida \& 30 patients $(81 \%)$ were multigravida. Among multigravidas $20(67 \%)$ had antecedent term pregnancy, 9 (30\%) had abortion \& 1 (3\%) had history of antecedent molar pregnancy (complete mole). Patients with antecedent molar pregnancy \& abortion presented after an interval of around 4-7 months. 19 patients (95\%) with history of previous full term deliveries presented after a period of $>13$ months \& 1 patient $(5 \%)$ presented within a period of 7-13 months. Table 1, reveals the characteristics of the sample size.

Table 1: Characteristic of sample size.

\begin{tabular}{|c|c|c|c|c|}
\hline Parameter & Group & No. & Mean & Range \\
\hline \multirow{3}{*}{ Age (years) } & $<20$ & 6 & \multirow{3}{*}{26.9} & \multirow{3}{*}{$19-45$} \\
\hline & $20-39$ & 26 & & \\
\hline & $>40$ & 5 & & \\
\hline \multirow{3}{*}{ Parity } & Primi & 7 & & \\
\hline & $1-4$ & 23 & & \\
\hline & $\geq 5$ & 17 & & \\
\hline \multirow{2}{*}{$\begin{array}{l}\text { Gest age } \\
\text { (weeks) }\end{array}$} & $1^{\text {st }}$ trimester & 20 & \multirow{2}{*}{$10 \pm 3.7$} & \multirow{2}{*}{$8-14$} \\
\hline & $2^{\text {nd }}$ trimester & 17 & & \\
\hline \multirow{3}{*}{$\begin{array}{l}\text { Fundal } \\
\text { height }\end{array}$} & Larger EGA* & 21 & & \\
\hline & Same EGA* & 13 & & \\
\hline & Smaller EGA* & 3 & & \\
\hline
\end{tabular}

*EGA: Expected Gestational Age

Thirty one patients (84\%) came with complaints of bleeding per vaginum after a period of amenorrhoea. 8 $(19 \%)$ patients had complaint of hyperemesis, $2(8 \%)$ of them presented with history of passage of vesicle. Four patients were asymptomatic \& diagnosed as a case of vesicular mole during routine sonography for amenorrhoea. Five patients were referred after suction and evacuation, with histopathology report of molar pregnancy. 
The mean gestational age was $10 \pm 3.7$ weeks, the GTD was most commonly (54\% of cases) diagnosed at the first trimester. Uterine size was larger than the gestational age in $57 \%$ of cases, the same size in $35 \%$ of cases and smaller than the gestational age in $08 \%$ of cases.

In GTD patients may show negative urine pregnancy test (UPT), as seen in our study where $8(30 \%)$ patients had negative UPT. This is due to the HOOK effect because of very high levels of beta-hCG (Hook effect is defined as falsely low values on an immunoassay when an overwhelming amount of antigen affects the binding capacity of the added antibody).

Out of 37 patient $29(78 \%)$ had complete mole \& $8(22 \%)$ had partial mole. The ratio of complete mole to partial mole was found to be $3.6: 1$. Out of 29 complete molar pregnancy 3 patients $(10.34 \%)$ progressed to gestational trophoblastic neoplasia (GTN), $2(5 \%)$ progressed to invasive mole and $1(3 \%)$ progressed to choriocarcinoma. The overall rate of gestational trophoblastic neoplasia was $8 \%$ (i.e. $3 / 37$ ). In this study no patients with partial hydatiform mole developed gestational trophoblastic neoplasia on follow up.

Beta hCG levels were elevated in all the cases - $23(62 \%)$ had levels more than 100000.

Complications seen in the patients suffering from GTD are summarised in Table 2.

Table 2: Complications associated with GTD.

\begin{tabular}{|ll|}
\hline Complications & \\
\hline Anaemia $(\mathrm{Hb}<10)$ & 20 \\
\hline Anaemia requiring blood transfusion & 7 \\
\hline Hyperthyroidism & 8 \\
\hline PIH & 1 \\
\hline Post s/e pulmonary edema & 2 \\
\hline Death & 1 \\
\hline ARDS & 1 \\
\hline
\end{tabular}

WHO scoring was done for all patients, 23 patients were scored more than 7 (high risk) and rest 14 patients were low risk patients as they scored less than 7. Thirty-two patients underwent primary treatment at our institute out of which 5 patients lost to follow up and 1 patient expired due to pulmonary embolism after suction and evacuation. Out of these 14 patients show falling titre of serum beta hCG and hence did not require any chemotherapy. 12 patients had high level of beta hCG after suction evacuation, hence they were given one cycle of prophylactic chemotherapy with methotrexate. Out of these, 9 patients showed complete remission after receiving prophylactic MTX. Only 3 patients had high beta hCG levels and they achieved complete remission after receiving 3 more cycles of MTX. These patients were given 2 more cycles of MTX after complete remission.
Five patients who were referred after suction evacuation were treated with MTX. Four patients responded well to MTX and achieve complete remission after 3 to four cycles. Only one patient did not responded to MTX and was treated with multiple agent therapy- EMACO regimen. She received 6 cycles of EMACO followed by hysterectomy with bilateral salpingo-oophorectomy with re-implantation of left ureter because of the persistent lesion on sonography \& MRI engulfing the left ureter leading to left hydroureter \& mild left side hydronephrosis.

On follow-up 5 patients attended early menopause, 16 patients regained normal menstrual cycle within 8 months of completion of treatment. 10 patients started regular menstrual cycle after 10 months of completion of treatment. One patient conceived and delivered a full term healthy baby after 2 years of treatment.

\section{DISCUSSION}

GTD is a rare disease with varied presentation, and clinicians are still faced with many challenges in management. It includes both benign and malignant forms. Early diagnosis of GTD by beta hCG, ultrasound and timely treatment with chemotherapy (single agent or multiple agent) results in $100 \%$ cure rate in low risk cases and $80-90 \%$ cure rate in high-risk cases. ${ }^{3}$

The incidence of GTD in our study was 1 in 600 pregnancies which was comparable to the study done by Rao et al. showing the incidence of GTD ranges from $1: 190$ to $1: 650$ deliveries. $^{4}$

Abnormal vaginal bleeding remains the most common presentation in the GTDs, $84 \%$ of cases in current study presented with vaginal bleeding, and this was in agreement with studies done by Debika Mukherjee et al. [5] where $88.6 \%$ patient presented with bleeding per vaginum, and by Moodley $\mathrm{M}$ et al. ${ }^{6}$ where $93.8 \%$ presented with this complaint.

Twenty one percent of the current study cases presented with hyperthyroidism, which was similar to the study done by Shahla Karim Al Alaf and Deman Ibrahim Omer in North Iraq $^{6}$ where $25 \%$ of women with GTD presented with hyperthyroidism. But in the study done by American cancer society (2009) less than $10 \%$ of women with GTDs presented with hyperthyroidism. ${ }^{7}$

The overall rate of gestational trophoblastic neoplasia was $8 \%$ (i.e. $3 / 37)$. Two $(5 \%)$ cases were of invasive mole and $1(3 \%)$ case was of choriocarcinoma. Two third $(66.66 \%)$ of cases of GTN were aged above 40 years. Chattopadhyay et al. in Saudi Arabia reported that the GTN was seen more frequently in the older age group. (More than 40 years). ${ }^{8}$

The beta hCG level was normalised after suction and evacuation in $14(38 \%)$ patients. Seventeen patients (46\%) required chemotherapy, 16 patients achieved 
complete remission with first line chemotherapy and one patient required second line chemotherapy with multiple agent (EMACO regimen) followed by hysterectomy. Thus complete cure rate in present study was seen in 31 out of $37(84 \%)$ patients. Mortality was seen in $2.7 \%$ (1 out of 37) patient. In a study performed by Bolis et al. 32month survival in patients with high risk was $88 \%$. $^{9}$ Shakuntala Chhabra \& Ambreen Qureshi, reported case fatality rate of $2.02 \%$ which was seen in advance malignancy. $^{5}$

\section{CONCLUSION}

Gestational trophoblastic disease's spectrum varies from benign to malignant disease, which can be treated successfully even in the presence of distant metastasis if diagnosed and treated on time. If it is not diagnosed on time, even hydatiform mole can be fatal. Hence it is important to diagnose and treat the condition early, as the curative rate is very high.

Funding: No funding sources

Conflict of interest: None declared

Ethical approval: The study was approved by the institutional ethics committee

\section{REFERENCES}

1. Berkowitz RS, Goldstein DP. Gestational trophoblastic neoplasia. In: Berek JS, Hacker NF, eds. Practical Gynecologic Oncology. 2nd ed. Baltimore, MD: Williams \& Wilkins; 1994: 441-468.
2. Grimes DA. Choriocarcinoma: epidemiology. J Reprod Med. 2002;39(3):155-62.

3. ACOG Practice Bulletin 53. Diagnosis and treatment of gestational trophoblastic neoplasms. Obstet Gynecol. 2004;103:1365-77.

4. Daftary SN, Padubidri VG Trophoblastic diseases In: Padubidri VG, Daftary SN, eds. Shaw's Text Book of Gynaecology. 13th ed. Chicago: J. \& A. Churchill Limited; 2004 248-259.

5. Shakuntala Chhabra \& Ambreen Qureshi, Gestational trophoblastic neoplasms with special reference to invasive mole. J Obstet Gynecol India. 2007;57(2):124-7.

6. Moodley M, Tunkyi K, Moodley J Gestational trophoblastic syndrome: an audit of 112 patients. A South African experience. Int J Gynecol Cancer. 2003 Mar-Apr;13(2):234-9.

7. American Cancer Society. How is gestational trophoblastic disease diagnosed? 2012. Available at: http://www.cancer.org/docroot/CRI. Accessed 26 September 2012.

8. Chattopadhyay SK, Sengupta BS, AL Ghreimil M, Edrees WB, Lmbourne A. Epidemiologic study of gestational trophoblasic diseases in Saudi Arabia. Surg Gynecol Obstet. 1988;167(5):393-8.

9. Bolis G, Bonazzi C, Landoni F, Mangili G, Vergadoro F, Zanaboni F, Mangioni C. EMA/CO regimen in hich-risk gestational trophoblastic tumor (GTT). Gynecol Oncol. 1988;31:439-44.

DOI: $10.5455 / 2320-1770 . i j r \operatorname{cog} 20140605$

Cite this article as: Shrivastava S, Gandhewar MR. Gestational trophoblastic disease: a profile of 37 cases. Int J Reprod Contracept Obstet Gynecol 2014;3:317-20. 